\title{
PAPER
}

\section{Potentially misleading extratemporal lobe lesions in patients with temporal lobe epilepsy}

\author{
T M Alsaadi, L M Bateman, K D Laxer, N M Barbaro, E J Austin, P A Garcia
}

See end of article for

authors' affiliations

J Neurol Neurosurg Psychiatry 2003;74:566-569

....................

Correspondence to: Dr T Alsaadi, Department of Neurology, University of California, Davis, 4860 Y Street, Suite 3700, Sacramento, California 95817, USA:

taoufik.alsaadi@

ucdmc.ucdavis.edu

Received 12 September 2002

Accepted

11 January 2003
From a series of 217 consecutive temporal resections for intractable epilepsy between 1993 and 2000, we identified all patients with large non-neoplastic extratemporal lesions. Only patients with known postsurgical outcomes with follow up for more than two years were included. Fifteen patients were identified. All patients had a history of medically refractory epilepsy with clinical and ictal evidence of mesial temporal seizure onset. Eleven patients had extratemporal lesions ipsilateral to the seizure focus, whereas four patients had the lesions contralateral to the seizure focus. Nine of the 15 patients had evidence of hippocampal atrophy on magnetic resonance imaging (MRI). Following temporal resection, nine of these patients $(60 \%)$ became seizure free (Engel class $1 \mathrm{~A})$, two patients were free of disabling seizures only (Engel class 1B), and two patients had a few early seizures but then became seizure free for at least two years (Engel class 1C). Two patients had significant improvement (Engel class 2). Thus, the finding of large extratemporal lesions on MRI was potentially misleading. When clinical semiology and ictal EEG recordings provide evidence of temporal onset seizures, anterior temporal resection should be considered in patients with extratemporal lesions.
$\mathrm{T}$ he use of high resolution magnetic resonance imaging (MRI) for the evaluation of patients with epilepsy has allowed the identification of structural brain lesions including tumours, vascular malformations, contusions, infarcts, and cortical dysplasias, as the aetiology of the epilepsy. ${ }^{1}$ The identification of such lesions may give the impression that these abnormalities are the source of the epilepsy. This view is supported by studies showing suboptimal surgical outcomes when these lesions are not completely resected, if they are the source of epilepsy. ${ }^{2}$ Occasionally, however, lesions are not the source of epileptic activity and may simply be incidental or unrelated to the seizure. $^{4}$

Earlier reports have shown better surgical outcomes when lesion resection was combined with standard temporal lobectomy in patients with extratemporal, extrahippocampal lesions associated with hippocampal atrophy (HA), referred to as "dual pathology". ${ }^{5}$ Similar conclusions were made in patients with small inaccessible extratemporal lesions. ${ }^{7}$ The best surgical approach for patients with large extratemporal lesions with and without HA is, however, unknown. We present 15 patients with extratemporal lesions who had a diagnosis of temporal lobe epilepsy confirmed by clinical and electrical criteria with good outcomes following surgery.

\section{METHODS}

From a series of 217 consecutive temporal resections for intractable epilepsy between 1993 and 2000, we identified all patients with large non-neoplastic extratemporal lesions. We excluded 203 patients with tumours, since most of these patients represent less diagnostic uncertainty and most of them become seizure free following resective surgery. ${ }^{8}$ Sixteen patients were identified. In this study, we included only patients with known postsurgical outcomes for more than two years. One patient was excluded due to loss of follow up, leaving 15 patients available for analysis in this study. We reviewed patients' demographics and clinical data, including age of onset of epilepsy, seizure description, and risk factors for epilepsy. Seizure semiology, interictal electroencephalogram
(EEG), and ictal EEG were analysed using long term video EEG telemetry monitoring.

\section{Clinical seizure characteristics}

All patients had one or more characteristic auras, particularly a rising epigastric sensation or an experience of change of reality or emotion. All had one or more automatisms, most often lip smacking, chewing, and fidgeting. Most patients had an initial blank stare or arrest of activity. These features have been particularly associated with mesial temporal lobe epilepsy. ${ }^{9}$

\section{Work up}

All patients underwent EEG recordings utilising the 10/20 surface electrode system with sphenoidal electrodes in selected cases. Ictal recordings were considered adequate for temporal onset localisation, if the ictal electrographic pattern fit the criteria previously described. This criterion can reliably and accurately localise most patients with temporal onset seizures. ${ }^{10}$ In eight cases where ictal onset could not be determined, an additional recording with intracranial electrodes was performed. MRI scans were examined for the presence of hippocampal atrophy and/or increased hippocampal T2 signal based on standard visual diagnostic criteria. ${ }^{11}$ When MRI showed normal appearing hippocampi or when the surface ictal recordings were not localising, other ancillary tests were performed, including positron emission tomography, and magnetoencephalography. All patients had extensive neuropsychological testing and an intracarotid amytal speech and memory test (Wada test). All patients had adequate memory function in the contralateral hemisphere. The patients' postsurgical outcomes were determined using Engel's outcome scores, as previously described. ${ }^{12}$ Follow up was achieved by review of the clinic visit notes and contact with the referring physician when necessary. The median follow up was 4 years (range $2-7$ years).

Abbreviations: $E E G$, electroencephalogram; HA, hippocampal atrophy $\mathrm{MRI}$, magnetic resonance imaging 


\begin{tabular}{|c|c|c|c|c|c|c|c|c|c|c|}
\hline Patient & $\begin{array}{l}\text { Age } \\
\text { (y) }\end{array}$ & Sex & $\begin{array}{l}\text { Age of } \\
\text { onset }(y)\end{array}$ & MRI & Interictal & $\begin{array}{l}\text { Ictal } \\
\text { surface }\end{array}$ & Invasive & Path & $\begin{array}{l}\mathrm{F} / \mathrm{U} \\
\text { months }\end{array}$ & Outcome \\
\hline 1 & 48 & $\mathrm{~F}$ & 15 & R P AVM & RT & RT & RT & Gliosis & 96 & $1 \mathrm{~A}$ \\
\hline 2 & 45 & $\mathrm{~F}$ & 15 & R F encephalomalacia L HA $+\uparrow$ sig & LT, RF & LT & - & MTS & 32 & $1 \mathrm{C}$ \\
\hline 3 & 47 & $M$ & 27 & Encephalomalacia RT R HA & RC & $\mathrm{RC}$ & RT & MTS & 32 & 1B \\
\hline 4 & 30 & $\mathrm{~F}$ & 3 & R P encephalomalacia R HA & RT & RT & - & Gliosis & 26 & $1 \mathrm{~A}$ \\
\hline 5 & 30 & $\mathrm{~F}$ & 1 & R PO encephalomalacia R HA & None & Diffuse & RT & MTS & 28 & $1 \mathrm{~A}$ \\
\hline 6 & 36 & $\mathrm{~F}$ & 10 & LF hamartoma & $L T>>B F$ & LT & LT & MTS & 32 & $1 \mathrm{~A}$ \\
\hline 7 & 45 & $\mathrm{~F}$ & 27 & R F encephalomalacia & RT & RT & RT & Gliosis & 68 & $1 \mathrm{~A}$ \\
\hline 8 & 50 & $\mathrm{~F}$ & 21 & B OCC heterotopias & LT & LT & - & Gliosis & 70 & $1 \mathrm{C}$ \\
\hline 9 & 50 & $\mathrm{~F}$ & 10 & L FTP encephalomalacia $\mathrm{R} \mathrm{HA}+\uparrow$ sig & RT & RT & - & Gliosis & 30 & 2 \\
\hline 10 & 40 & $\mathrm{~F}$ & 3 & L FTP encephalomalacia & LT & Diffuse & LT & Gliosis & 76 & 2 \\
\hline 11 & 41 & $\mathrm{~F}$ & 26 & B OCC cystic lesions R HA & RT & RT & - & Gliosis & 92 & $1 \mathrm{~B}$ \\
\hline 12 & 42 & $M$ & 22 & $\mathrm{~L}$ posterior $\mathrm{F}$ porencephaly $\mathrm{L} H \mathrm{H}+\uparrow$ sig & $\mathrm{LT}>\mathrm{RT}$ & LT & - & MTS & 30 & $1 \mathrm{~A}$ \\
\hline 13 & 31 & $\mathrm{~F}$ & 12 & L P AVM, R HA $+\uparrow$ sig & RT & Diffuse & RT & MTS & 26 & $1 \mathrm{~A}$ \\
\hline 14 & 30 & $\mathrm{~F}$ & 15 & R OCC encephalomalacia R HA & RT & RT & - & MTS & 48 & $1 \mathrm{~A}$ \\
\hline 15 & 40 & $M$ & 5 & LF encephalomalacia & RT & RT & - & MTS & 92 & $1 \mathrm{~A}$ \\
\hline
\end{tabular}

R, right; L, left; B, bilateral; P, parietal; F, frontal; T, temporal; OCC, occipital; HA, hippocampal atrophy; Sig, signal.

\section{RESULTS}

Fifteen patients were identified, aged 30-50 years (mean 40.3 years) with age of seizure onset at 13 months to 27 years (mean 14.8 years), and seizure duration at the time of this study 12-40 years (mean 26 years). Four patients had a history of a significant head injury resulting in loss of consciousness for more than 24 hours before the onset of their habitual seizures: three secondary to motor vehicle accidents in their 20s and one due to injury with a baseball bat in early childhood. Two patients had a history of febrile convulsions (ages 5 months and 4 years). All patients had extratemporal lesions on MRI: nine had areas of encephalomalacia (two fronto-parietal-temporal, three frontal, one parietal, three parieto-occipital), one had bilateral occipital
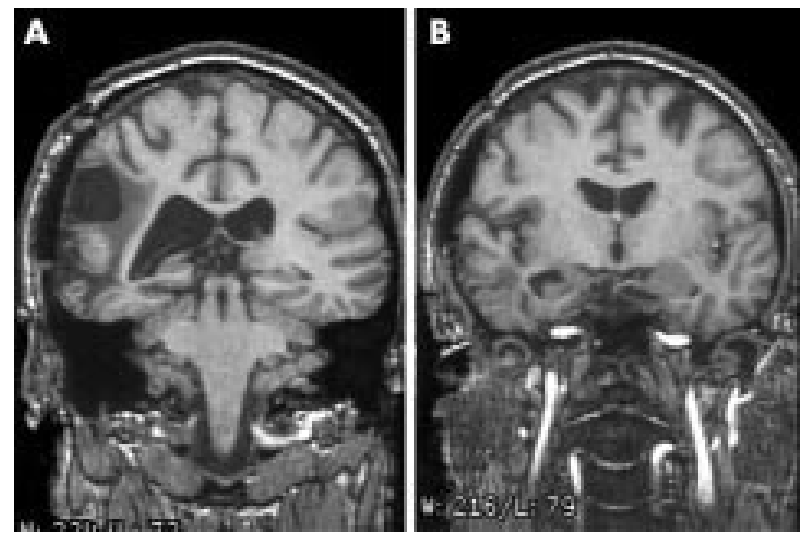

Figure 1 Patient 3: 47 year old man with history of seizures since the age of 27 . T1 weighted coronal MRI images showing large area of encephalomalacia surrounding a large poroncephalic cyst in the right temporoparietal region $(A)$ as well as small right hippocampus (B).

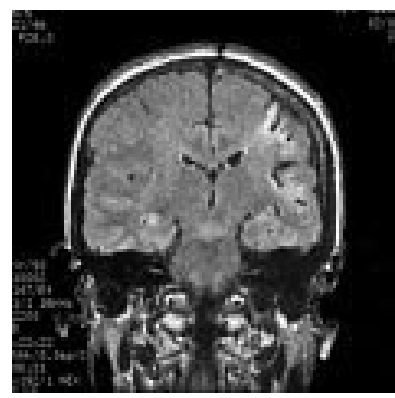

Figure 2 Patient 9: 50 year old woman with history of seizures since the age of 21 . Fluid attenuated inversion recovery (FLAIR) sequence coronal MRI showing large area of increased signal in the left cortical, subcortical frontotemporal opercula compatible with gliosis/encephalomalacia as well as increased signal in the small right hippocampus. heterotopias, one had occipital cystic lesions, one had a frontal hamartoma subtotally resected 20 years previously, one had posterior frontal porencephaly, and two had parietal arteriovenous malformations. Of these patients, nine had evidence of hippocampal atrophy. In eleven patients the extratemporal lesions were ipsilateral to the side of temporal lobe seizure onset; whereas the remaining patients had their lesions contralateral to the seizures focus (patients 2, 9, 13, and 15).

None of the patients' habitual seizures have changed over the course of their disease. All patients had evidence of temporal seizure onset based on ictal surface recordings (seven patients), and intracranial recordings with subdural grids placed over the lesions, combined with depth electrodes placed in the hippocampus via a posterior approach (eight patients). The interictal surface EEG showed epileptiform activity well lateralised to the ipsilateral temporal ictal focus in all but two patients; patient 2, and in patient 5 there was no epileptiform activity recorded. Patients 1 and 6 had previously undergone lesionectomies but continued to have intractable seizures following the original surgery. Patient 6 underwent selective amygadalohippocampectomy, whereas the other 14 patients underwent standard anterior temporal lobectomies.

Following temporal resection with at least two years follow up, nine patients $(60 \%)$ became completely seizure free (Engel class 1A), two patients were free of disabling seizures only (Engel class 1B), and two patients had a few early seizures but then became seizure free for at least two years (Engel class 1C). Two patients only had significant improvement (Engel class 2). Eight of the Engel class 1 patients (1A, 1B, and IC included) had pathological findings of mesial temporal sclerosis, six of whom had evidence of hippocampal atrophy on MRI. Pathological specimens in
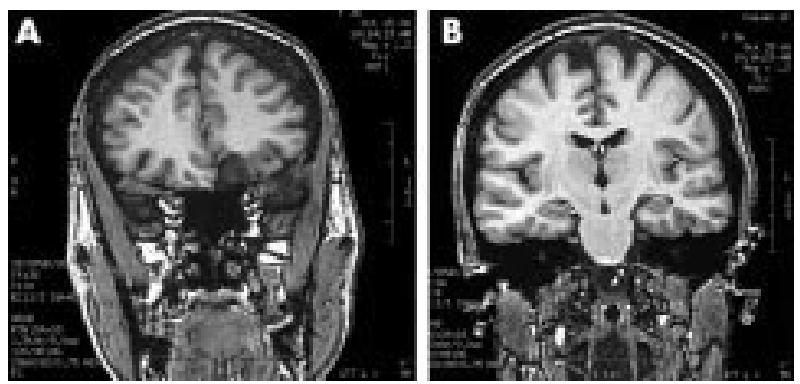

Figure 3 Patient 6: 36 year old woman with history of seizures since the age of $10 . T 1$ weighted coronal MRI images showing left frontal hamartoma (A) as well normal appearing hippocampi (B). 
the remaining patients showed only mild gliosis with no appreciable neuronal loss. Table l summarises the patients' characteristics and evaluations. Figures 1, 2, and 3 show representative MRI images from patients 3, 9, and 6, respectively.

\section{DISCUSSION}

This series provides evidence for the lack of a cause-effect relation in some patients with temporal lobe epilepsy and extratemporal lesions. In a previous study, 18 patients were found to have non-contiguous lesions remote from the epileptic activity, as evidenced by brain mapping utilising subdural electrodes. ${ }^{13}$ Two of these patients only underwent temporal lobectomy without removing the lesion; both of these patients became seizure free. In another study, 11 of 15 patients became seizure free following temporal lobectomy combined with lesionectomy, while two of 10 patients became seizure free following temporal lobectomy alone. ${ }^{5}$ Unlike those in our study, all patients in that study had evidence of hippocampal involvement by MRI measures or by pathological examination; the study of Awad et al, however, did not provide any information about the MRI findings. ${ }^{13}$

Nine of our patients had hippocampal atrophy (HA) on MRI, while the remaining patients had normal appearing hippocampi. Only a few of our patients had MRIs in early 1993, possibly before our MRI technique was optimised to include high resolution MRI to detect subtle HA. It is possible that HA was undiagnosed in a few of our patients. The finding of "dual pathology" on MRI has been noted in $15-30 \%$ of patients with intractable epilepsy. ${ }^{14}$ It has been described mostly in patients with temporal or occipital lesions, but it is not typically encountered in patients with frontal or parietal lesions. ${ }^{15}$ Furthermore, it is certainly unexpected to find HA contralateral to the lesion, as was the case in four of our patients (patients 2, 9, 13, and 15). The pattern of seizure propagation may explain the finding of HA in patients with occipital lobe lesions. This, however, has often not been observed in patients with frontalparietal lesions, perhaps because there are less abundant direct anatomical connections between the hippocampus and the frontal or the parietal lobes to facilitate seizure spread between these structures. Secondary epileptogenesis has been described in animal models of epilepsy, but in humans this concept is not well understood. ${ }^{16}$ We do not believe that this hypothesis is the aetiology of our patients' seizures since most of our patients became free of disabling seizures without resection of the extratemporal lesions.

Our findings differ from others ${ }^{56}$ in that nine of our patients only had evidence of hippocampal atrophy by MRI, while the other six patients had "single pathology" with no MRI evidence of temporal lobe pathology. The other studies, however, report on patients with dual pathology who underwent combined temporal lobectomy and lesionectomy, and in a small number of patients, temporal lobectomy without lesionectomy. It is likely that many more of our patients who are seizure free did have MTS despite negative pathology, possibly because of inadequate surgical specimens that were obtained in earlier cases.

Structural brain lesions identified during the evaluation of patients with partial epilepsy are usually epileptogenic, with some exceptions. Fifteen of our 217 temporal lobectomy cases had strong evidence to the contrary, in that $73 \%$ of these patients became free of disabling seizures (Engel class 1A, 1B) after temporal lobectomy, whereas two patients (13\%) became seizure free after having a few early seizures (Engel class 1C). However, we cannot say the same for sure in patients without seizure free outcomes. The presence of extratemporal lesions may be incidental or potentially the result of a diffuse process, such as ischaemic or traumatic, with a selective predilection for the mesial temporal lobe. In view of the growth of epilepsy surgery programmes, it should be emphasised that in patients with intractable epilepsy and structural brain pathology, adequate evaluation should be performed before surgeons proceed to perform lesionectomies. Epilepsy surgery requires a careful multidisciplinary evaluation that includes neurological, psychological, psychiatric, and ictal EEG, among others. Imaging studies using MRI, for example, are still important tools for surgical evaluation. However, their results should be interpreted with caution in that the finding of a lesion on an imaging study does not prove that this lesion is the source of epilepsy. Results of all the other tests should be integrated carefully before proceeding with surgical treatment.

We realise the limitations of this study since we are not able to ascertain the incidence of temporal lobe epilepsy in all of our patients with extratemporal lesions. We therefore cannot say how frequent this finding is. Nevertheless, our surgical results suggest that temporal resection is a rational approach to this group of patients in whom complete lesion resection combined with temporal lobe surgery would cause considerable morbidity. Our patients have pathologies that might be predicted to have both temporal and extratemporal lesions; this should be a "red flag" for those considering jumping to lesionectomy in patients with extratemporal lesions.

In summary, we think that temporal resection should be considered in patients with extratemporal lesions, provided that all the clinical and ictal EEG criteria support the temporal onset of the seizures. We believe that concordant ictal EEG and clinical semiology are necessary to define the seizure focus for the patient to be considered a candidate for seizure surgery. This series of patients confirms that this principle is important, even in patients with gross structural lesions.

\section{Authors' affiliations}

T M Alsaadi, Department of Neurology, University of California, Davis, USA

L M Bateman, K D Laxer, E J Austin, P A Garcia, Department of Neurology, University of California, San Francisco, USA

N M Barbaro, Department of Neurological Surgery, University of California, San Francisco

Competing interests: None declared

\section{REFERENCES}

1 Boon PA, Williamson PD, Fried I, et al. Intracranial, intraaxial, space-occupying lesions in patients with intractable partial seizures: an anatomoclinical neuropsychological, and surgical correlation. Epilepsia 1991;32:467-76

2 Awad IA, Nayel MH, Luders $\mathrm{H}$. Second operation after the failure of previous resection for epilepsy. Neurosurgery 1991;28:510-18.

3 Obana WG, Laxer KD, Cogen PH, et al. Resection of dominant opercular gliosis in refractory partial epilepsy. J Neurosurg 1992;77:632-9.

4 Engel J, Driver MV, Falconer MA. Electrophysiological correlates of pathology and surgical results in temporal lobe epilepsy. Brain 1975;98:129-56.

5 Li LM, Cendes F, Andermann F, et al. Surgical outcome in patients with epilepsy and dual pathology. Brain 1999;122:799-805.

6 Cascino GD, Jack CR, Parisi JE, et al. Operative strategy in patients with MRI-identified dual pathology and temporal lobe epilepsy. Epilepsy Res 1993; 14:175-82.

7 Fish D, Andermann F, Oliver A. Complex partial seizures and small posterior temporal or extratemporal structural lesions: surgical management. Neurology 1991:41:1781-4.

8 Britton JW, Cascino GD, Sharbrough FW, et al. Low-grade glial neoplasms and intractable partial epilepsy: efficacy of surgical treatment. Epilepsia 1994;35: $1130-5$

9 Noachtar S, Pfander M, Luders HO. The localizing value of the abdominal aural and its evolution: a study in focal epilepsies. Neurology 2002;58:271-6 
10 Risinger MW, Engel I Jr, Van Ness PC, et al. Ictal localization of temporal lobe seizures with scalp/sphenoidal recording. Neurology 1989;39:1289-93

11 Garcia PA, Laxer KD, Barbaro N, et al. Prognostic value of qualitative magnetic resonance imaging hippocampal abnormalities in patients undergoing temporal lobectomy for medical refractory seizures. Epilepsia 1994; $35: 520-4$

12 Engel J Jr, Van Ness PC, Rasmussen T, et al. Outcome with respect to epileptic seizures. In: Engel J Jr, ed. Surgical treatment of the epilepsies, 2nd edn. New York: Raven Press, 1993:609-21.
13 Awad IA Rosenfield J, Ahl J, et al Intractable epilepsy and structural lesions of the brain mapping, resection strategies, and seizure outcome. lesions of the brain mapping,

14 Raymond AA, Fish DR, Stevens JM, et al. Association of hippocampal sclerosis with cortical dysgenesis in patients with epilepsy. Neurology 1994;44:1841-5

15 Williamson PD, Boon PA, Thadani VM, et al. Parietal lobe epilepsy: diagnostic consideration and results of surgery. Ann Neurol 1992;31:193-201.

16 Morrell F. Secondary epileptogenesis in man. Arch Neurol 1985:42:318-35.

\section{HISTORICAL NOTE}

\section{Hermann Oppenheim (1858-1919)}

$\mathrm{O}$ ppenheim's name is perpetuated by his eponymous sign of pyramidal tract lesions, and by the disease bearing his name, Oppenheim's disease.

Amyotonia congenita $^{1}$ is a congenital, sometimes familial, disorder, characterised by muscular hypotonia and hypoplasia without atrophy. It results in floppy infants with excessive mobility of joints and consequent abnormal postures. Some children who survive more than 18 months from the onset may improve and are often designated benign congenital hypotonia. Oppenheim clearly described myotonia congenita, a separate condition, in his book, ${ }^{2}$ but some confusion between the disparate disorders pervades the early literature. Myotonia congenita (Thomsen's disease) was described by Asmus Julius Thomsen (1815-1896) in 1876 in his own family, who showed episodic myotonic contractions, precipitated by cold, pressure, and percussion of enlarged muscles: later portrayed as "The Infant Hercules". It is now doubtful if Oppenheim's disease is a distinct entity; ${ }^{3}$ it is one of several disorders causing the "the floppy infant". When the primary defect is in the cord, the condition is known as WerdnigHoffmann disease. The term amyotonia congenita should now be applied to non-progressive myopathies. Confusing causes of the floppy infant syndrome include glycogen storage diseases, the atonic-astatic syndrome of Foerster, and the congenital non-progressive myopathy (Batten and Turner), nemaline myopathy, and central core disease.

\section{Oppenheim's sign}

Oppenheim also drew attention to the association of spasticity with hyper-reflexia:

"Stiffness, rigidity, or spastic condition of the muscles can be recognised from exaggeration of the tendon phenomenon."

In 1902 he reported the sign that perpetuates his name; ${ }^{4}$ observed in pyramidal tract disease in which Babinski's sign (earlier recorded by E. Remak) was equivocal:

"If one draws the handle (or shaft) of a percussion hammer over the inner surface of the leg from the upper margin of the tibia downwards, one sees in the healthy person either no movement at all in the foot and toes or else a plantar flexion of the toes. If the irritation is made strongly enough, distinct plantar flexion of the toes is the rule, but sometimes it is necessary to divert the attention of the patient to obviate voluntary movements. Whereas in persons with the symptom complex of spastic hemiparesis, this reflex movement of the muscles is extended to the great toe and adducts or abducts the foot."
Oppenheim made other, more important, contributions, and with Erb was considered the leading figure of German neurology. In 1890 he diagnosed the first brain tumour to be removed in Germany by Koehler, and he fostered the development of neurosurgery. In a controversial monograph on the traumatic neuroses, ${ }^{6}$ he contended that psychic disturbances following trauma were due to organic (molecular) changes in the brain: a theory now commonly accepted, but then vehemently opposed with much acrimony by Charcot, Mendel, and Nonne. He coined the phrase dystonia musculorum deformans ${ }^{7}$ (described by Schwalbe), describing the "dromedary gait". Oppenheim also studied disseminated sclerosis, poliomyelitis peripheral nerve lesions, and precociously used Ehrlich's Salvarsan in neurosyphilis.

Of enormous influence and scholastic merit was his Lehrbuch der Nervenkrankheiten. It ran to seven German editions and was translated into Russian, Spanish, Italian, and English $^{2}$ (three editions). The distinguished American neurologist William Gibson Spiller (1863-1940), when challenged to write a neurology textbook, remarked, "When I can write a better book than Oppenheim's, I'll do so."

Hermann Oppenheim (1858-1919) was born in Warburg, Westphalia. He was a major figure in neurology. After studying at Göttingen, Berlin, and Bonn, he trained at Berlin's Charité under Carl Westphal. During Westphal's protracted terminal illness, Oppenheim took charge of his clinic, but was not rewarded with his Chair, because of the official governmental anti-Semitism, which overruled the university's nomination of Oppenheim as Professor Extraordinarius. Deprived of any official teaching post he practised in a private clinic in Berlin. Many valued scientific publications emerged so that it became the recognised international centre for neurology.

\section{J M S Pearce}

304 Beverley Road, Anlaby, Hull HU10 7BG, UK; jmspearce@freenet.co.uk

\section{References}

1 Oppenheim $\mathbf{H}$. Über allgemeine und lokalisierte Atonie der Muskulatur (Myatonie) im frühen Kindesalter. Monatsschrift für Psychiatrie und Neurologie, Basel, 1900;8:232-3.

2 Oppenheim H. Lehrbuch der nervenkrankheiten. Berlin: S. Karger, 1894 (translated 2nd edn: Textbook of nervous disease. New York: G E. Steckert, 1911).

3 Greenfield JG, Cornman T, Shy GM. The prognostic value of the muscle biopsy in the 'floppy infant'. Brain 1958;81:461-84.

4 Oppenheim $\mathbf{H}$. Zur pathologie der Hautrefelexe an den unteren Extremitäten. Mschr Psychiat Neurol 1902;12:518-30.

5 McHenry LC. Garrison's history of neurology. Springfield IL: Charles C. Thomas, 1969:270-300.

6 Oppenheim H. Die traumatischen neurosen nach den in Nervenklinik der Charité. Berlin: Hirschwald, 1889

7 Oppenheim H. Ueber eigenenartige Krampfkrankheit des kindlichen und jugendlichen Alters (Dysbasia lordotica progressiva, Dystonia Musculorum Deformans). Neurol Centrabl 1911;30:1090. 